\title{
Fighting for Their Future: An Exploratory Study of Online Community Building in the Youth Climate Change Movement
}

\author{
Emily Wielk \\ George Washington University, USA
}

\author{
Alecea Standlee \\ Gettysburg College, USA
}

DOI: http://dx.doi.org/10.18778/1733-8077.17.2.02

\section{Keywords:}

Digital Ethnography;

Climate Activism;

Youth; Social Media;

Social Movements

\begin{abstract}
While offline iterations of the climate activism movement have spanned decades, today online involvement of youth through social media platforms has transformed the landscape of this social movement. Our research considers how youth climate activists utilize social media platforms to create and direct social movement communities towards greater collective action. Our project analyzes narrative framing and linguistic conventions to better understand how youth climate activists utilized Twitter to build community and mobilize followers around their movement. Our project identifies three emergent strategies, used by youth climate activists, that appear effective in engaging activist communities on Twitter. These strategies demonstrate the power of digital culture, and youth culture, in creating a collective identity within a diverse generation. This fusion of digital and physical resistance is an essential component of the youth climate activist strategy and may play a role in the future of emerging social movements.
\end{abstract}

Emily Wielk is a current graduate student in the Women's, Gender, and Sexuality Program (Public Policy track), as well as a teaching assistant in the Department of Sociology at George Washington University. Her research has focused on digital activism and the intersections of sport and gender using primarily qualitative research methodologies. Currently, she is working on book chapters for an anthology on women's leadership in the 1950s at the advent of second-wave feminism.

email address: wielke@gwu.edu

\begin{abstract}
Alecea Standlee is an Assistant Professor of Sociology at Gettysburg College, in the United States. Her scholarship examines the implications of the integration and normalization of online communication technologies in the lives of Millennials and Gen Z. Specifically, her works seek to discuss the impact of strategic surveillance by corporate media platforms to collect, distribute, manage, and utilize individual-level data on participants' perceptions of privacy, individual identity representation, and group affiliation. She has published in New Media \& Society, Inside Higher Ed, Journal of Contemporary Ethnography, and elsewhere. email address: astandle@gettysburg.edu
\end{abstract}




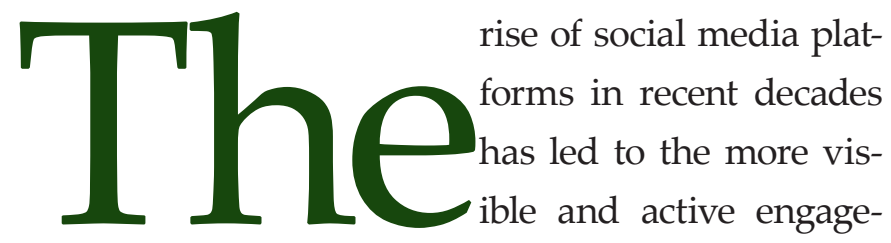

ment of youth climate activists in critical issues facing the global environment and has fundamentally transformed environmental conversations. While youth activists were engaged in the fight for climate justice in the past (Blakemore 2018), the inception of the digital age, where technological advances in society have become inextricably embedded into the fabric of people's lives, has allowed social media to change the landscape of social movement mobilization. In 2018, Greta Thunberg pioneered the youth "Strikes for Climate" by protesting outside the Swedish Parliament. Within a year of her solo strikes, Thunberg became a prominent leader in youth climate change activism by documenting her journey on Twitter, where she built a network to promote her cause and generate a community of followers online. Thunberg is not an outlier, though. With the power of online media at their fingertips, current youth activists, many in high school or younger, are calling adults to action to right the wrongs otherwise left for future generations (Astor 2018).

Our research considers how youth climate activists utilize social media platforms to create and direct social movement communities towards greater collective action. This exploratory project examines narrative framing and linguistic conventions to better understand how youth climate activists utilize Twitter to build community and mobilize followers around their movement. Specifically, this project advances broader understandings of how social movements emerging on digital platforms could generate salient narratives that can build communities across global networks. In the following article, we will address some of the strategies used by youth activists to communicate and build a collective identity within their online communities. We utilize theories by Goffman (1959), McLuhan (1967; 1994), and Castells (2000; 2002), to understand the creation of digital networks and communities and to assess the changing nature of public figures within climate change movements.

This project uses digital ethnographic techniques to assess the development of the online youth climate change movement on Twitter. The main research questions are: 1) How do youth climate change activists use Twitter to create community and shared identity among followers? and 2) How is Twitter used strategically to create narratives that mobilize community action among this group of followers? Specifically, we examine what strategies youth activists use to build narratives around climate change as a way to mobilize support, with a focus on the linguistic conventions shared by the group, the creation of shared norms, and how they evoke emotional responses in followers.

Using digital ethnographic techniques, we assess the thematic content embedded in the Twitter feeds of seven prominent youth climate activists to examine how leaders of the movement build community in an online environment. Our analysis reveals three primary strategies employed by the activists that prove effective in building this change-oriented coalition around global climate action: (1) projecting an activist identity through the content generated in their tweets; (2) using both on- and offline tools to create multiple narratives that seek to attract and engage a global community of youth climate activists; and (3) engaging in broad political conversations using evocative emotional narratives to build connections that resonate with followers. While each activist develops and implements these strategies uniquely, they serve as a common thread throughout the activist Twitter accounts and may construct a roadmap for future activists attempting to establish an online social movement. 


\section{Digital Technologies, Youth Activism, and Emerging Social Movements}

Online digital technologies have transformed contemporary social interactions in complex ways. Platforms, such as Twitter, serve multiple purposes, such as information sharing, user-generated content, and real-time interactions amongst individuals (Murthy 2012; Gil de Zúñiga, Copeland, and Bimber 2013; McFarland and Ployhart 2015), and expanding opportunities for public engagement (Effing, van Hillegersberg, and Huibers 2011; Kim and Adam 2011; Finlayson 2019). Social media sites offer a set of functions that transform information sharing and content generation. Hashtags, retweets, and graphics are common rhetorical strategies and linguistic functions employed online to build narratives via social media platforms (Shapp 2014; Bonilla and Rosa 2015; Yang 2016). These functions offer different methods of sharing content to weave a narrative between connected or disparate Twitter users around a given issue (Bonilla and Rosa 2015; Yang 2016). Some research suggests that the strategic functions and tools available on Twitter have proven effective in other social movements (Bonilla and Rosa 2015) and continue to play an important role in contemporary social movement organizing.

Some scholars argue that with the creation of more advanced digital technologies, the Internet has paved the way to connect publics online from anywhere, sparking a desire for individual or collective action and transforming social movement development (Park, Lim, and Park 2015). Social media has allowed individuals to share their concerns, facilitate discussions, and motivate publics by creating large online networks and expanding the reach of their activism (Bonilla and Rosa 2015; Yang 2016). This structure of creating emerging social movements reduces the hierarchical nature (Castells 2002) and allows all users to share their ideas, contributing to global communities for social change (Chon and Park 2019). Murthy (2012), however, argues that social media is a tool for "ordinary" people to create content and share information rather than just individuals with significant power. It also allows ordinary people to connect with larger social networks using social media as a mediator, which suggests that online interactions can build equally meaningful social networks as offline interactions (Kim and Adam 2011; Willems 2019).

However, other work focuses on the harmful implications of data collection and management on issues of privacy and control (Pasquale 2016). This kind of surveillance may have implications for social movement organizations as their members are targeted by corporate and governmental interests. Further, the use of algorithms by social media companies boosts some messages and devalues others, which can have implications on how data spread (Pariser 2011; Pasquale 2016). Scholars who focus on online movements have identified issues related to "slacktivism" or "clicktivism," which allow for low stake and symbolic engagement in social movements, can be a side effect of online organizing (Christensen 2011; Cabrera, Matias, and Montoya 2017), as well as the fragility of larger-scale social movements that seek to translate into offline action (Tüfekçi 2017). This can increase overall participation, but leads to low investment (Christensen 2011).

Other scholars argue that analyses of technological impact become a form of technological determinism, presuming that technological change drives social progress (Wyatt 2008). The debate around theories of technological determinism is complex, and we do not embrace this model. Instead, we situate our work within the broader debate by arguing that technology can play a role in changing social norms, which can be at times progressive, and at other points re- 
gressive. Further, we argue that social change and technology are reflexive rather than linear in structure. Specifically, evidence suggests that changes in communication and information technologies have been linked to changes in communication behavior and information spread (Haythornthwaite and Wellman 2002; Park et al. 2015; Velasquez and LaRose 2015). Our work examines these changes and patterns within youth climate change activism.

Although the long-term implications of online social movements are still unfolding, some research suggests that social media allows activists to create alternatives to traditional gatekeeping tactics exemplified in former social movements pre-social media (Park et al. 2015; Cox 2017). Similar to information control tactics evidenced in corporate institutions (Pasquale 2016), activists use social media to manipulate public opinion and mobilize communities. Emerging social movements that appear to benefit from the strategic use of information distributed via social media sites include \#OccupyWallStreet, \#ArabSpring, \#BlackLivesMatter, and \#metoo, attesting to the breadth and depth of online social movements in sparking global activism rather than simply reaching more localized communities or publics (Frangonikolopoulos and Chapsos 2012; Park et al. 2015; Cox 2017).

As digital technologies continue to expand, an increase in their use to connect users and spread information on global issues allows for a shift in how activist communities-or communities for social change-form (Chon and Park 2019). Activism, as expressed by Chon and Park (2019), focuses on the need to build collective understandings of what social transformations need to occur to create environments for transformational social change. By using the new digital platforms, as well as more traditional means of media engagement, activists share information that serves as the foundation for action, uniting the group into a single collective, reconceptualizing the action-oriented nature historically necessary for the emergence of social movements, and leading to new understandings of commitment to the cause (Seo et al. 2014; Velasquez and LaRose 2015; Chon and Park 2019).

Further, social media provides an outlet for youth to share their concerns, generate knowledge, and be more politically active since they are not yet able to vote and face logistical limitations in face-to-face participation (Seo et al. 2014; Velasquez and LaRose 2015). The implications for understanding youth collective action through social media sites have yielded insights into the future of global activism and the social capital that can be generated online to mobilize public support for social change within underrepresented populations (Seo et al. 2014). Contemporary social movement literature demonstrates that the impact of digital activism is still unfolding. This project on the youth-led climate change movement contributes to this ongoing discussion by bringing together two fascinating aspects of social movement development. We examine the role that youth are playing in the climate change movement globally and how they use digital tools of communication as a mechanism to promote their message, mobilize publics, and form community through online networks.

Theoretically, we situate this project at the nexus of scholarship between McLuhan (1967; 1994), Goffman (1959), and Castells (2000; 2002) who develop theoretical perspectives that together explore the relations between the self, collective identity, and online communication. McLuhan (1967; 1994) emphasizes the importance of assessing the medium when analyzing online interactions. These online mediums disseminate messages uniquely, transforming how group communication occurs. Goffman's (1959) regions of 
performance-the front stage and backstage-demonstrate how identity and the self are accentuated or suppressed during interactions. Online performances are shaped by the role of the media in mediating performance for the audience, navigating its features to curate front (online) and back (offline) stage performances. Castells (2000) integrates these concepts to understand the interactions between the Internet and collective identity through emerging digital platforms. Further, the Internet expands global connectivity, which produces a new language and medium through which individuals can negotiate meanings and identities (Castells 2002). This provides an important framework to assess changes in the ways that social protests can take hold online and in the streets.

\section{Research Design and Methods}

This project uses digital ethnography within an online field site, Twitter. Digital ethnography utilizes traditional ethnographic approaches, specifically observation and fieldnotes within a digital environment (Murthy 2012; Hampton 2017). Digital observation techniques require nuanced data collection that in- cludes elements of content analysis to effectively capture the nature of digital communication (Hampton 2017). We began by developing research questions regarding the strategies employed by youth activists to build narratives around climate change. We were particularly interested in the way such narratives mobilized support, the creation of shared norms and vocabularies, and evoked emotional responses of followers.

The Twitter field site serves to replicate a traditional ethnographic field site by framing a community to be studied within the broader youth climate change movement. Seven activists serve as the informants to the norms and practices of the broader youth climate change community. We selected a purposive sample of online climate activists based on news coverage throughout 2019 to determine which faces and voices were the most prominent in the movement. Each Twitter account represents an individual that belongs to the online community, and their interactions are tracked through Twitter's functions - tweets, retweets, mentions, and hashtagsto identify interactions among users. Data were collected by extracting one month of tweets from these seven youth leaders in the movement.

\section{Social Media Activist Statistics}

Table 1. Overview of Twitter Data for Each Youth Climate Activist

\begin{tabular}{|c|c|c|c|c|c|c|}
\hline Activist & Activist Username & Age & $\begin{array}{c}\text { Country of } \\
\text { Origin }\end{array}$ & $\begin{array}{l}\text { Tweets during } \\
\text { Time Frame }\end{array}$ & $\begin{array}{c}\% \text { Original } \\
\text { Tweets }\end{array}$ & Followers \\
\hline Lilly Platt & @lillyspickup & 11 & Netherlands & 124 & $98 \%$ & $11.5 \mathrm{~K}$ \\
\hline Haven Coleman & @havenruthie & 13 & USA & 53 & $96 \%$ & $11.4 \mathrm{~K}$ \\
\hline Isra Hirsi & @israhirsi & 16 & USA & 134 & $77 \%$ & $34 \mathrm{~K}$ \\
\hline Alexandria Villaseñor & @AlexandriaV2005 & 14 & USA & 156 & $65 \%$ & $38.3 \mathrm{~K}$ \\
\hline Holly Gillibrand & @HollyWildChild & 13 & Scotland & 186 & $45 \%$ & $14.3 \mathrm{~K}$ \\
\hline Greta Thunberg & @GretaThunberg & 16 & Sweden & 119 & $40 \%$ & $3 \mathrm{M}$ \\
\hline Jamie Margolin & @Jamie_Margolin & 17 & USA & 2203 & $2 \%$ & $25.9 \mathrm{~K}$ \\
\hline
\end{tabular}

Source: Self-elaboration. 
Data collection occurred over a 30-day period using NCapture linked to NVivo to capture tweet data and compile a dataset of tweets for each identified activist in the study. Digital ethnographic observation techniques provide a new lens to observe and be in conversation with the community to assess emerging themes and patterns through computer-mediated social interactions (Pink et al. 2015). Given the exploratory nature of the research, we used coding, memoing, and thematic development strategies from Emerson, Fretz, and Shaw (2011) to analyze the curated tweet content (tweets, retweets, and media). Hashtags were analyzed as a recurring pattern rather than exploring their algorithmic nature to develop unique tweet threads. Based on the most frequent patterns identified during the coding process that had strategic implications (Emerson et al. 2011), we identified the three strategies discussed in this article.

This project raises some ethical concerns in accessing the Twitter data of minors via their social media accounts. Since the accounts of these individuals were public and accessible through a public domain (Twitter), there was no expectation of privacy from observation and analysis of the content being generated-participants were engaged in public conversations in a public way. Since we acknowledge the voices of the original activists, the specific tweet language is easily traced back to the individual activists through a simple search, so the identities of the activists are not kept confidential and their names are used in the discussion of the data. This model of data collection was approved by a federally recognized Institutional Review Board (IRB).

\section{Interpretive Analysis}

Our analysis begins with a series of claims that frame our work. First, we argue that the examination of the activist narratives and strategies from multiple theoretical perspectives allows for rich insight into the construction of identity and community on online platforms. We believe that careful discursive analysis of social media, specifically tweets, reveals key insights that allow us to identify patterns of behavior that build community, which is central to the creation of activist movements. We also argue that the evolution of new digital technologies to disseminate a particular discourse to large publics has an important role to play in the future of social movements. In this work, we identify several salient strategies and activist narratives that are used to effectively build and mobilize communities for change.

We identified three major discursive narratives that demonstrate the use of Twitter to develop community and create motivations for mobilization around global climate issues. First, our findings suggest that the strategic presentation of self by the online activists exists along a rhetorical spectrum that ranges from "full-time activist" to "teenager with an activist orientation." Secondly, activists employ a narrative that creates community in both digital and offline spaces, utilizing the specific characteristics of Twitter, such as hashtags, retweet functions, character limits, and embedded multimedia. Finally, we identified patterns of communication that focused on the deployment of emotional language and evoked emotional connections as a call to action. Taken together, these patterns underscore the degree to which technology, discursive narratives, and strategic communications create a sense of global community.

\section{Constructing Activist Identities Online}

Through the strategic creation of identity and thoughtful presentations of the self, the activists 
in our study created a sense of connection to other young people and other climate change activists. Furthermore, activists employed a range of presentations, which varied from activist to activist. Activists situated themselves within this spectrum, and in doing so created a relatable identity that allows for a sense of comradery and connection with their followers. Using the framework provided by Goffman's (1959) theory on the presentation of self, Twitter allows for the analysis of the front stage performance created by each activist in approximately 280 characters or less, to gain a following and build a community around the global climate crisis. Further, social media acts as a mediator for its users (Murthy 2012), allowing them to craft messages that create an image for followers to see as the core of their online identities, and is often presumed by the public to be their offline identity as well. By analyzing the tweets from each activists' accounts, we examine the ways in which they choose to present themselves via an online platform. This allows us to identify where each individual falls within a spectrum of different modes of activism, from "full-time climate activist" to "teenager with an activist or political orientation." We use this spectrum to evaluate how closely the activists' accounts meet the standards of their self-described identities as "activists." Some express very specific activist identities in their Twitter bios (e.g., @GretaThunberg self-described as "16-year-old climate and environmental activist with Asperger's \#climatestrike \#fridaysforfuture").

Thunberg, and other activists such as Villaseñor and Gillibrand, are examples of those who present themselves as "full climate activists." They frame their positions within the school strikes for climate, but rarely in other instances draw attention to schoolwork or other conversations typically had by teenagers. Rather, they present themselves (and self-identify in their Twitter bios as "environmental" or "climate" activists) as full-blown climate activists on social media with an orientation towards inspiring younger generations to act. Thunberg's tweet captures this sentiment:

School strike week 68. They say more than 500000 people showed up tonight in Madrid!

\#fridaysforfuture \#climatestrike \#schoolstrike4climate \#cop25 [@GretaThunberg, https://t.co/YAxPZt3fOU']

While their "backstage" performances are not available via social media accounts, the actions they have taken in offline protests, the messages they craft via social media, and their self-described identity as an activist demonstrate how they strategically craft a front stage identity as serious activists. The content they generate online, in particular, is a selection of curated messages to build credibility and community amongst followers, by presenting themselves as knowledgeable and acceptable youth representatives of the climate change movement.

Other activists present a strong activist orientation online, but also situate this commitment to activism within an explicitly teenage identity. Margolin is particularly effective at presenting in this manner while still ensuring that her tweets focus primarily on climate injustice. She focuses on balancing being a "normal teenager" who has to do schoolwork and miss class to speak up about the climate crisis:

Check this @TheEnergyTalk episode out!

"We discuss how Jamie manages to balance her work as an activist while being in her final year of high school

\footnotetext{
${ }^{1}$ All tweets presented in this work will include links to the original source material and are subject to Twitter Terms of Service, which specify reuse of content on Twitter Services is allowed with appropriate acknowledgments.
} 
and dealing with the pressures that come with always being in the public eye in the era of social media." [@Jamie_Margolin, https://twitter.com/Jamie_Margolin/status/1198384129470951424]

This approach draws attention to the strain that the climate crisis places on younger generations, outside of the already stressful aspects of being a teenager. By specifically presenting herself as a teenager with a powerful voice, she seeks to inspire others to do the same in their communities. She also effectively reminds followers that she is not an adult, but is willing to step up and speak out about issues that matter to her on a global, public stage online, and increasingly offline. In this way, Margolin constructs her presentation of self as a struggle between her backstage performance as a "normal teenager" merged with her front stage, mediated performance, balancing teenage life and activism. Strategically, this has the potential to highlight both the importance of climate change activism to youth culture and to motivate adults to engage in the movement by evoking a sense of responsibility in older followers.

At the other end of the spectrum, identified as "teenagers with an activist orientation," activists show their continued support and willingness to raise awareness around climate injustice, but do not present the identity of "climate activist" as a pervasive part of their identity, at least as it is portrayed online. Activist Isra Hirsi effectively demonstrates this as her tweets heavily focus on diverse aspects of political activism, with a central focus on climate activism. She also is not shy to highlight the "real" her, as seen through videos or "TikToks" with her mom:

${ }^{2}$ A new social media platform to share "short-form mobile videos." today on making my mom tiktok famous, we learned a tiktok dance. can you tell it's going well? @IlhanMN [@israhirsi, https://t.co/Ixeal0CtGb]

Hirsi, unlike the other activists analyzed, is uniquely situated as the daughter of a United States Congresswoman, and this may have implications in her self-presentation. Hirsi more so than the others shows glimpses of her personal life behind her activist identity-presumptively a glimpse into Goffman's (1959) backstage-but only via a limited social media lens which primarily showcases dance videos or "TikToks." So, similar to what is seen on Margolin's account, the "backstage" performance is still mediated via social media and may be better understood as a strategic front stage performance to garner favor among followers.

Further, the personas created online by each of the activists are often centered around "events" as Twitter has created a platform based on an "event-society" and the shared human experience as a way to interact and communicate with one another (Therborn 2000; Murthy 2012). Thus, no matter where the activists fall on the spectrum, they are using their social media presence as a platform to connect with others in a shared manner, whether it be frustration over the current climate crisis, frustrations over growing up too fast, or frustrations over the broader political environment. They are focused on engaging a variety of followers at home and across the globe to join in the youth climate movement.

\section{Engaging in Protest: Digitally and Physically}

A second major theme that we identified is the persistence of the youth climate change movement's use of a combination of very specific and unique online (digital) tools to inspire offline (physical) 
and digital protests, within a global context. These activists present multiple narratives through their tweets that attract and engage a global community of youth climate activists. Each account shows a blend of two strategies, hashtags and retweets, to share their message, promote major events, and garner an increased following to help organize a movement that moves the public to act. The structure of Twitter allows for the creation of a community that exists within a liminal space and blends online and offline experiences. This is effective for activists because it allows for a more complex and experiential sense of connection among participants. This experience of both engaging online narratives and sharing their collective action offline encourages connection and a sense of community among youth climate activists.

Using the framework put forth by McLuhan (1967; 1994), the structure and framework of Twitter have emerged as an important medium for this particular analysis. McLuhan's statements on the importance of analyzing the medium of communication in understanding a message are highly relevant. McLuhan claims that communication between individuals and groups occurs not only through language, but also via the symbolic nature of communication mediums. McLuhan applies the concept of media broadly and argues that technologies shape how humans understand their world, and the information that they receive within it (McLuhan 1994). Examining the specific nature of the Twitter medium allows us to advance our understandings of how the message and mobilization within the youth climate movement occur, offering key insights for the future of online social movements. Twitter, as the communication medium, must be understood within the context of emerging information communication technologies (ICTs) (Carty
2011), where the cultural shifts to online communication across broader, more disparate networks globally serve to advantage the youth climate movement. Second, given that offline organizing (i.e., "Strikes for Climate") is a marquee aspect of the youth climate movement in addition to the online presence, Twitter as the medium through which this community organizing and activist mobilization occur presents as an extension of the physical suggested by McLuhan (1967). Twitter's popular tools and functions serve as their own unique medium to transfer ideas within the movement to global audiences.

Activists employ several Twitter tools-hashtags and retweets - to create this global online network and advance the conversation using a variety of narrative forms over the month-long timeframe of our data collection. Hashtags specifically prove to be a popular organizing tool that allows users, whether activists themselves or followers, to make connections between events and actions, to maintain a conversational thread around the same topic, and span geographic locations all using the same online "tag." The use of particular "contentious" hashtags directly drawing together stories from major events, be they political, natural, or cultural, relating to the purpose of the movement is more influential than employing hashtags that relate to more "routine" topics such as "climate" generically (Yang 2016). An advantage of online organizing around hashtags is that the spread of information can occur more rapidly than more traditional methods of communication used in social movements, as well as can reduce the hierarchical and limited nature of participation in the conversation. While not all hashtags generate popularity (Yang 2016), the ones in our sample that did work to advance the narrative around an event were able 
to connect users from across the world and instill plans for future action and engagement amongst those followers. Key events during the analyzed timeframe are the global climate strikes and the UN Climate Change Conference (COP25):

Week 45 of my \#schoolstrike4climate and \#schoolstrike4nature in Fort William. Yesterday we went on strike for four hours in solidarity with youth around the world. My message to all the adults now is to VOTE for our FUTURES in the \#GE2019. \#FridaysForFuture

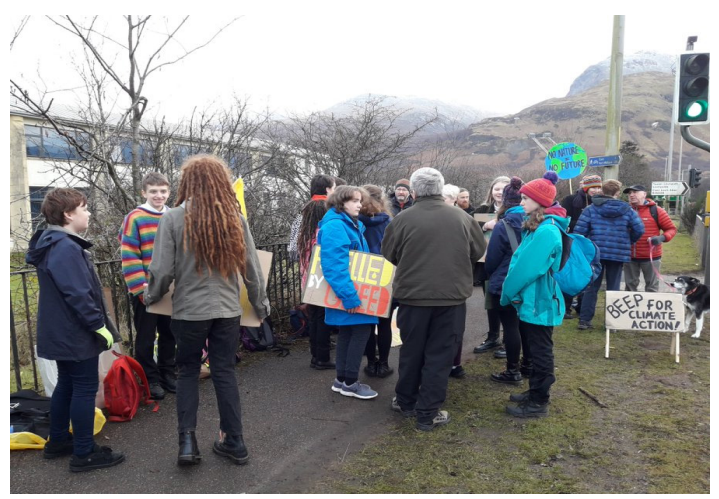

[@HollyWildChild, https://twitter.com/HollyWildChild/status/1200822077189697539?s=20]

This use of hashtags (\#schoolstrike4climate and \#FridaysForFuture, in particular) as a common thread amongst activists globally makes it easier to document much of their offline protests and actions using individual social media handles. Additionally, as the literature (Bonilla and Rosa 2015; Yang 2016) suggests, the use of images or pictures adds to the narrative by documenting offline action and inspiring other followers to join the offline movement as well. If the story or event portrayed in the tweet is supposed to evoke a sense of urgency for future action within the community, hashtags usually include a verb expressing this strong sense of force or urgency (Yang 2016), here seen in the use of the word "strike." Gillibrand's tweet demonstrates how the use of rhetorical devices to engage audiences, particularly given the limited text afforded on Twitter, serves a greater purpose and imbues increased meaning in the emerging narratives of these activists and the youth climate change community. This can best be understood within the work of McLuhan (1994) who argues that the medium in which communication occurs sends a message to the receiver that is separate from the actual ideas communicated verbally or visually, but is still important. He argues that media create an extension of human senses that continually transform and reshape social processes and individual perceptions of the world. The extension itself, or the ability to see/hear and experience distant images or voices via technology reshapes human perceptions in ways that are independent of the actual content of the images or voice (McLuhan 1994).

Hashtags or tweets do not have to evoke a physical action as a response, but are also used to connect events and spread awareness or information within the movement. Hashtags as a medium of communication create a sense of connection and experience of linking distant things that exist independently of the message contents. For example, the use of \#COP25 garnered a lot of attention in early December, creating an emotionally-charged narrative (Frangonikolopoulos and Chapsos 2012; Park et al.; Yang 2016; Cox 2017) where youth activists note the injustices they faced while attending the UN Climate Change Conference:

Happening now: Youth activists from all around the world storm the stage at \#COP25 to demand real climate action! Dear leaders, your empty words will not solve this crisis. \#YourVoteOurFuture [Retweet from @FridayforFuture by @AlexandriaV2005, https://twitter.com/FridayForFuture/status/1204693889392754690] 
An utter failure.

\#COP25 \& conferences like it are intended to be actual negotiations to urgently drawdown global carbon emissions - not cocktail parties to make politicians feel better about themselves as they squash dissent $\&$ sell off our futures to fossil fuel interests. [Retweet from @AOC by @israhirsi, https://twitter.com/AOC/ status/1205904994685345802]

Such tweets target the inadequacies of climate change policies globally and call out specific political leaders either by name or their Twitter handle to open a conversation about the lack of action taken to date. As both these tweets show, youth activists are frustrated with the continued verbal assurance that change will come, but that no firm action to reverse policies or problems that are currently fueling climate change has been taken. In pointing to such inadequacies, the activists may build the same sense of distrust and frustration amongst their followers and inspire them to join the offline protests. The use of the hashtag \#COP25 connects individual stories over the multi-day conference through which the activist community, as well as the general public, could reorient itself from a community/collective to understanding the individual experiences as expressed through this online medium (Bonilla and Rosa 2015).

While hashtags prove an effective method of creating a vast conversation around these events, retweets are also a popular method of connection, most notably shown by Jamie Margolin (@Jamie_Margolin), as well as Greta Thunberg (@GretaThunberg) and Holly Gillibrand (@HollyWildChild). Their accounts show that less than half the content they generate is originally created by them. Instead, they focus on promoting and redistributing content produced by other users within and even outside the youth cli- mate movement to build their narratives. Margolin's numbers are especially intriguing, as she generates only 3\% (50 tweets) of unique content disseminated in her 2,203 tweets during the timeframe. This shows the power afforded to activists online to connect and share the messaging of other activists or users instantaneously when there is an agreed-upon message being portrayed. Additionally, retweets aid in coalition-building around major and minor activists in the movement as a whole.

As Carty (2011) introduces in her research, the emergence of ICTs has impacted the future of emerging social movements in a way unseen in prior movements. The overlap between digital and physical activism presented by these activists through their social media accounts suggests a shift in the way social movements will be sustained by activists. This analysis focuses on the way that these activists have used their social media accounts to bridge the why and the how by using the unique tools offered on Twitter-retweets, hashtags, replies, mentions, and more-to bring users together from across the globe and continue to showcase the worthiness of the cause, particularly from the youth perspective.

\section{Emotional Narratives as a Call to Action}

In addition to depicting an implicit focus on the political nature of the climate movement across the globe via large events and protests, activists are not shy in weaving into their narratives the major concerns happening to our environment in real-time and utilizing images and emotional appeal to create a connection. Framing this strategy within McLuhan's (1994) conception of a communicative medium, the message conveyed in these tweets serves a purpose. Given the limited character count afforded to those who utilize Twitter (280), graphics, links 
to news media, or videos present a powerful message to audiences, again proving to be the extension of the physical deterioration of the Earth via online visualizations. This use of medium allows for significant control and deployment of narratives that evoke strong emotions, which emerge as a powerful tool for community building. The use of emotions, including fear, guilt, and even anger, creates a powerful discourse around climate activism that results in a moral imperative. This use of emotions is effective in creating a connection among young activists, but even more importantly calls to action older activists by utilizing the desire to protect the future for young people. This turns the "youth" of the climate change leaders into a powerful asset, narratively speaking, in implementing their goals.

In part, this is done by illustrating the severe consequences of global warming and the impending climate crisis. Each activist uses this strategy sparingly from November to December 2019, with Thunberg the most likely to return to the realities of what is happening to our climate, whether using original tweets or retweets:

The air quality in Rozelle (inner Sydney) this afternoon was 2552! Hazardous is 200+!!! Where are you @ScottMorrisonMP? \#ThisIsNotNormal \#ThisIsClimateChange [Retweet from @StrikeClimate by @GretaThunberg, https://twitter. com/Travis4Climate/status/1204291757510479873]

Thunberg's tweets point mainly to the devastating wildfires that burned through Australia, but also broader issues of $\mathrm{CO} 2$ emissions and rising sea levels. By linking to a news article that explored the devastation unfolding in Sydney, Thunberg effectively advances a major concern of the movementthe future of our environment as a viable place to live-to millions in an instant and uses the inter- active features of the medium, Twitter, to her advantage. Other activists follow a similar approach to Thunberg by presenting a panicked or angered response to global climate issues:

Oxygen in the oceans is being lost at an unprecedented rate, with "dead zones" proliferating and hundreds more areas showing oxygen dangerously depleted, as a result of the \#ClimateEmergency and intensive farming, experts have warned.

\#ActNow [Retweet from @ScotlandXr by @HollyWildChild, https:/twitter.com/ScotlandXr/status/1203362108404043776]

Appealing to anger and frustration is a common approach taken by activists (Yang 2016), showcasing the severity and urgency of their claims online. However, in some instances, humor is also a way to engage social media audiences in conversations about tangible actions that could be taken against the negative effects of climate change:

@medicsforfuture @zaynecowie Yes please! I am English we moved from London a few years ago! It will be great we could even go on the canal and do some plastic fishing! [@lillyspickup, https://twitter.com/lillyspickup/status/1200038436943458304?s=20]

This proves an effective approach to weaving a narrative around Lilly's choice of activism: a more individualistic approach where she often cites individual strategies and actions that can be taken to ensure that the public is aware and engaging in the change that needs to occur in local communities and across the globe. Additionally, in encouraging specific ways that the public could get involved to help reverse the impacts of climate change, Lilly creates a powerful sense of community around a particular cause or action that people could tangibly partake in. 
However, fear and concern, rather than jest or encouragement, emerge as the most consistent and effective tool for community building in our data. Specifically, a growing fear of the future for youth, and the determination of youth to reclaim the power to reverse course. This fear manifests as a rallying cry among younger generations, an emotional appeal that attests to the uncertainty of their future and the actions that need to be taken right away. In general, these activists point to the insufficiency of policies regarding the climate that are created and implemented by older generations through traditional political processes that often favor business interests over the climate. Calls for action are demonstrated in many tweets by the seven activists in the study, similar to these:

Every election is a climate election. Vote for your children. Vote for the planet. Vote for future generations. Vote for humanity.\#GE2019\#UKElection[@GretaThunberg, https://twitter.com/GretaThunberg/status/1205068776787582976?s=20]

My shopping list for \#BlackFriday AKA \#BuyNothingDay Join the climate justice movement in resisting consumerism today.

Constantly buying things we don't need is destroying our planet.

Skip the fads, and put the planet and life on earth first. \#BuyNothing [@Jamie_Margolin, https://t.co/40kgGqWWwM]

These calls to action, rooted in a fear of the future, are strategically used to engage with political activism. Specifically, they demand that adults of voting age consider their responsibility towards young people and their futures. This creates a narrative of protectionism, in which voting adults are reminded of their social responsibility to young people. This highlights how social media has proven to be a particularly important avenue for youth activists to express political dissent and urge others to vote since they do not have a direct voice in current political processes worldwide. While embracing their identity as young people may result in stigma from some areas, the emotional appeals that are tied to youth identity are effective in creating a sense of community and urgency within their social environment.

\section{Conclusion}

This project contributes to ongoing discussions on emerging forms of social activism by examining the role of youth culture and digital technologies. The recent increase in social movements turning to digital platforms to expand their mobilization and community-building efforts has raised many questions regarding the practicality of online activism sparking offline action. While traditional theoretical understandings of social movements offer an important analytic framework for online social movements, Carty's (2011) conception of advancing social movement theory by fusing the various theoretical perspectives to analyze ICTs functions as the best starting point to assess digital activism.

While climate activism has spanned decades in offline iterations of the movement, online youth involvement through social media platforms has transformed the landscape of emerging social movements. Our project identifies three emergent strategies used by youth climate activists that appear effective in engaging activist communities on Twitter: (1) projecting an activist identity through the content generated in their tweets; (2) disseminating information and documenting offline protests in an online forum that inspires followers and ignites action for change; and (3) engaging in broad political conversations and utilizing emotional narratives to build a connection that resonates with the base of followers the movement wants to attract. 
These strategies have several implications. First, they build a common narrative about the fear that young people have about their future on Earth, given that climate change may render it unlivable in their lifetime. This narrative of fear, rather than instilling hopelessness and apathy, has given rise to belief in the power of youth, and the idea that they will collectively rise up, which resonates with younger generations and older allies across the globe. This is evidenced by localized offline protests springing up in countries across Europe, Africa, Australia, and beyond. Further, the message and dissemination of information, images, and videos prove to be an important means to engage followers in an online forum and increasingly in participation in offline events. While this does not include all youth, it demonstrates the power of digital culture, and youth culture, in creating a collective identity within a diverse generation. This fusion of digital and physical protest is an essential component of the youth climate activist strategy and may serve as the foundation for the future of emerging social movements.

Despite the importance of these implications, some significant limitations to this exploratory project exist. First, due to the small sample size, and the specific nature of this community ethnography, the results have limited generalizability. Additionally, due to the emerging and evolving nature of social movements and technology, the long-term implications of this study are yet to be identified. This research naturally lends itself to a longitudinal study regarding the success of the youth climate change movement to further analyze the effectiveness of the community-building and narrative strategies employed.

A common critique of predominantly online activism is the concept of "slacktivism" (Christensen

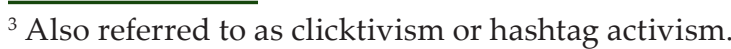

2011; Cabrera et al. 2017), which suggests that the use of online hashtags, or other mechanisms of interacting with a social media post-likes, retweets, replies, et cetera-is not a sustainable form of activism. Some argue that such techniques provide a guise of action or make the individual "feel good" about participating as opposed to mobilizing on the ground. With this critique in mind, the fusion of an online presence to share information and stories related to global climate activism and offline action, whether it is taking to the streets every Friday, attending legislative conferences, or organizing locally, has the potential to be an effective combination to enact real change in the future without falling victim to the issues embedded in slacktivism. Bonilla and Rosa (2015:7) point out in reference to \#BlackLivesMatter: "[Social media] allowed a message to get out, called global attention to a smaller corner of the world, and attempted to bring visibility and accountability to repressive forces," a strategy that is also employed via these activists' tweets calling out global leaders at major events or through more pointed Twitter exchanges.

Additionally, further quelling fears of online activist critics, these activists identify the offline actions happening frequently across the globe, despite such events not gaining attention from more traditional news media. However, unlike other digital social movements that are impacted by online interaction, but are devoid of a continued offline presence (e.g., \#metoo), the youth climate movement has wielded social media as an organizing tool similar to that of \#OccupyWallStreet, \#ArabSpring, and \#BlackLivesMatter in its ability to disseminate information (Frangonikolopoulos and Chapsos 2012; Bonilla and Rosa 2015; Park et al. 2015; Cox 2017). Specific to the climate movement is the global nature of the issue, and thus its ability to reach a global population in its efforts, further supporting a need for the fusion 
of the two strategies. Prominent figures within the youth climate change movement utilize communication methods within the Twitter platform that contribute to the visibility and growth of the movement. Activist identity, the dissemination of information, and connecting with broader political and emotional narratives all play a role in the emergence of this group as a visible voice within the broader climate change movement.

In past movements, the need for a central social movement organization to guide and organize the development of the messaging was an essential

\section{References}

Astor, Maggie. 2018. “7 Times in History When Students Turned to Activism." New York Times, March 05. Retrieved February 18, 2021 (https://www.nytimes.com/2018/03/05/us/student-protest-movements.html).

Blakemore, Erin. 2018. "Youth in Revolt: Five Powerful Movements Fueled by Youth Activists." National Geographic, March. Retrieved February 18, 2021 (https://www.nationalgeographic. com/culture/article/youth-activism-young-protesters-historic-movements).

Bonilla, Yarimar and Jonathan Rosa. 2015. “\#Ferguson: Digital Protest, Hashtag Ethnography, and the Racial Politics of Social Media in the United States." American Ethnologist 42(1):4-17.

Cabrera, Nolan L., Cheryl E. Matias, and Roberto Montoya. 2017. "Activism or Slacktivism? The Potential and Pitfalls of Social Media in Contemporary Student-Activism." Journal of Diversity in Higher Education 10(4):400-415.

Carty, Victoria. 2011. Wired and Mobilizing: Social Movements, New Technology, and Electoral Politics. New York: Routledge.

Castells, Manuel. 2000. The Rise of the Network Society. Malden, MA: Blackwell Publishers.

Castells, Manuel. 2002. "Series Editor Preface: The Internet and the Network Society." Pp. xxix-xxxi in The Internet in Everyday component of social movements, but youth climate activists have challenged this idea through their current movement-building tactics. While the need for offline organizing cannot be overlooked, trends-as seen through this project-present a compelling case for a significant online presence in future organizing efforts. As McLuhan (1967) and Castells (2000; 2002) point out, the Internet, the self, and society have become so interconnected it would be ill-advised to ignore the importance of social media as key storytelling and community-building environments for emerging social movements in the future.

Life, edited by B. Wellman and C. Haythornthwaite. Malden, MA: Blackwell Publishers.

Chon, Myoung-Gi and Hyojung Park. 2019. "Social Media Activism in the Digital Age: Testing an Integrative Model of Activism and Contentious Issues." Journalism and Mass Communication Quarterly 97(1):1-26.

Christensen, Henrik S. 2011. "Political Activities on the Internet: Slacktivism or Political Participation by Other Means?" First Monday: Peer-Reviewed Journal On the Internet 16(2). Retrieved February 18, 2021 (https://firstmonday.org/article/view/3336/2767).

Cox, Jonathan M. 2017. “The Source of a Movement: Making the Case for Social Media as an Informational Source Using Black Lives Matter." Ethnic and Family Studies 40(11):1847-1854.

Effing, Robin, Jos van Hillegersberg, and Theo Huibers. 2011. "Social Media and Political Participation: Are Facebook, Twitter and YouTube Democratizing Our Political Systems?" Retrieved February 18, 2021 (https://link.springer.com/chapter/10.1007/978-3-642-23333-3_3).

Emerson, Robert M., Rachel I. Fretz, and Linda L. Shaw. 2011. Writing Ethnographic Fieldnotes, $2^{\text {nd }} \mathrm{ed}$. Chicago: University of Chicago Press.

Finlayson, Alan. 2019. "Rethinking Political Communication." Political Quarterly 90:77-91. 
Frangonikolopoulos, Christos and Ioannis Chapsos. 2012. "Explaining the Role and the Impact of Social Media in the Arab Spring." Global Media Journal: Mediterranean Edition 8(1):10-20.

Gil de Zúñiga, Homero, Lauren Copeland, and Bruce Bimber. 2013. "Political Consumerism: Civic Engagement and the Social Media Connection." New Media and Society 16(3):488-506.

Goffman, Erving. 1959. The Presentation of Self in Everyday Life. New York: Anchor Books.

Hampton, Keith N. 2017. "Studying the Digital: Directions and Challenges for Digital Methods." Annual Review of Sociology 43(1):167-188.

Haythornthwaite, Caroline and Barry Wellman. 2002. "Part I: Moving the Internet Out of Cyberspace-The Internet in Everyday Life: An Introduction." Pp. 3-41 in The Internet in Everyday Life, edited by B. Wellman and C. Haythornthwaite. Malden, MA: Blackwell Publishers.

Kim, B. Joon and Farida Adam. 2011. “Social Media, Social Design and Social Construction: A Dialectic Approach for the Use of Social Media in the Public Sector." The International Journal of Technology, Knowledge, and Society 7(3):65-78.

McFarland, Lynn A. and Robert E. Ployhart. 2015. "Social Media: A Contextual Framework to Guide Research and Practice." Journal of Applied Psychology 100(6):1653-1677.

McLuhan, Marshall. 1967. The Medium Is the Massage: An Inventory of Effects. New York: Penguin Books.

McLuhan, Marshall. 1994. Understanding Media: The Extensions of Man. Reprint. Cambridge, MA: MIT Press.

Murthy, Dhiraj. 2012. "Towards a Sociological Understanding of Media: Theorizing Twitter." Sociology 46(6):1059-1073.

Pariser, Eli. 2011. The Filter Bubble: What The Internet Is Hiding From You. New York: Penguin Books.
Park, Se Jung, Yon Soo Lim, and Han Woo Park. 2015. “Comparing Twitter and YouTube Networks in Information Diffusion: The Case of the 'Occupy Wall Street' Movement." Technological Forecasting and Social Change 95:208-217.

Pasquale, Frank. 2016. The Black Box Society: The Secret Algorithms That Control Money and Information. Cambridge, MA: Harvard University Press.

Pink, Sarah et al. Digital Ethnography: Principles and Practice. Washington, DC: Sage Publishing Limited.

Seo, Hyunjin et al. "Teens' Social Media and Collective Action." New Media and Society 16(6):883-902.

Shapp, Allison. 2014. "Variation in the Use of Twitter Hashtags." Qualifying Paper in Sociolinguistics. Retrieved February 18, 2021 (https://s18798.pcdn.co/shapp/wp-content/uploads/ sites/18562/2020/09/Shapp_QP2_Hashtags_Final.pdf).

Therborn, Göran. 2000. "At the Birth of the Second Century Sociology: Times of Reflexivity, Spaces of Identity, and Nodes of Knowledge." British Journal of Sociology 51(1):37-57.

Tüfekçi, Zeynep. 2017. Twitter and Tear Gas: The Power and Fragility of Networked Protest. New Haven, CT: Yale University Press.

Velasquez, Alcides and Robert LaRose. 2015. "Youth Collective Activism through Social Media: The Role of Collective Efficacy." New Media and Society 17(6):899-918.

Willems, Wendy. 2019. “'The Politics of Things': Digital Media, Urban Space, and the Materiality of Publics." Media, Culture, and Society 41(8):1192-1209.

Wyatt, Sally. 2008. “Technological Determinism Is Dead, Long Live Technological Determinism." Pp. 165-180 in The Handbook of Science and Technology Studies, edited by E. Hackett et al. Cambridge, MA: MIT Press.

Yang, Guobin. 2016. "Narrative Agency in Hashtag Activism: The Case of \#BlackLivesMatter." Media and Communication 4(4):13-17.

\section{Citation}

Wielk, Emily and Alecea Standlee. 2021. "Fighting for Their Future: An Exploratory Study of Online Community Building in the Youth Climate Change Movement." Qualitative Sociology Review 17(2):22-37. Retrieved Month, Year (http://www.qualitativesociologyreview.org/ENG/archive_eng.php). DOI: http://dx.doi.org/10.18778/1733-8077.17.2.02 